\title{
A theoretical framework of romantic creativity: Dyadic creativity in romantic relationships and plausible links with wellbeing
}

\author{
Nicolas B. Verger · Raffi Duymedjian
}

\begin{abstract}
Everyday creative behaviours seem to be associated with high levels of wellbeing. Yet, the effects of creativity on wellbeing remain largely unknown, notably at a dyadic level, and particularly in the context of romantic relationships. Previous research has studied the effects of creativity on romantic relationships but has been limited by the two main epistemological assumptions that we present in this article. Consequently, very little is known about the effect of a form of creativity that may occur at a dyadic level in a romantic relationship, and that may have implications in the science of human flourishing. In other words, the research field lacks a theoretical framework for studying the effect of creativity in romantic relationships on wellbeing. The present theoretical framework aims to fill this gap by proposing a dyadic dimension of creativity embedded within wellbeing: romantic creativity. Romantic creativity is conceptualised as an observable, quantifiable, yet non-product-hierarchic phenomenon. It is defined as a dyadic process which favours new and meaningful directions in a romantic relationship through dynamics of discovery and self-expansion in one or both members of the dyad. This article describes the epistemological foundations of this theoretical framework and draws on existing research on self-expansion and the neuroscience of wellbeing to hypothesise the processes that might account for the effect of romantic creativity on human flourishing. We also identify two possible ontological perspectives for research on romantic creativity. The present article proposes that romantic creativity might help dyads to flourish through the processes implied in homeodynamics and dyadic self-expansion.
\end{abstract}

Keywords: creativity, wellbeing, dyad, romantic relationships, self-expansion

\section{Introduction}

Everyday creative behaviours connect to high levels of wellbeing (Conner et al., 2018; Richards, 2010). For many scholars, creativity - defined as the ability to produce novel/original and useful/meaningful ideas and/or products in a social context - constitutes the pinnacle of selfactualisation and individual wellbeing (Amabile, 1982; Forgeard \& Elstein, 2014; Plucker et al., 2004; Richards, 2010; Runco \& Jaeger, 2012). Abraham Maslow (1958), for instance, conceptualised a healthy mind as a mind of creative ideas, which he called the "healthiest creativeness" (p. 38). Along the same lines, research in art therapy has highlighted the effects of art as a tool for clinical rehabilitation (Darewych \& Riedel Bowers, 2018; Potash et al., 2014). For example, the visual arts have been shown to reduce negative symptoms among patients with schizophrenia (Richardson et al., 2007). Writing poetry has been suggested as helpful in aiding individuals to reprocess and express painful emotions (Carroll, 2005) and writing about emotional experiences seems to foster both physical and mental health (Pennebaker, 1997). Other 
theorists have viewed prolonged engagement in creative endeavours as characterised by perceptions of the dilatation of time (a sense of "flow"), and as encouraging feelings of elation in individuals, thus contributing to their wellbeing (Csikszentmihalyi, 1988, 1990). More recent evidence has associated everyday forms of individual creativity with positive emotions and feelings of vitality (Conner et al., 2018; Conner \& Silvia, 2015).

The effects of creativity on wellbeing, however, remain largely unknown, notably at a dyadic level, ${ }^{1}$ and particularly in romantic relationships. As we will see, research in this field lacks a theoretical framework with which to study the effect of romantic relationship creativity on wellbeing. Ontologically, what does it mean to be "creative" in a romantic relationship? Epistemologically, what are the manifestations of "romantic creativity", and how can they be measured? To what extent might romantic creativity contribute to wellbeing, and how is it similar to - and different from - other manifestations of creativity? These questions underpin the ensuing proposal for a novel theoretical framework of a dyadic form of creativity: romantic creativity. In this article, we put forwards a working definition of romantic creativity as a dyadic process which favours new and meaningful directions in a romantic relationship through dynamics of discovery and self-expansion in one or both members of the dyad. This definition is further developed in the following sections.

Three main sections in the article articulate this romantic creativity framework. The first section presents the epistemological foundations of romantic creativity, explaining why such a concept is needed, how it can be defined, alongside the epistemological foundations upon which it is based. The second section presents two ontological perspectives for future research. It describes the hypothetical mechanisms of romantic creativity in its relationship with selfexpansion and wellbeing via a review of supportive evidence from psychology and the neuroscience of wellbeing. The third section concludes the paper by summarising some of the ways in which this framework of romantic creativity contributes to the science of creativity and wellbeing, discussing some study limitations, and suggesting future research directions. By utilising the lens of romantic relationships, this framework aims both to invite researchers to consider an ontological and epistemological view of creativity that is complementary to individual creativity, and to address the still-neglected study of dyadic-forms of creativity on wellbeing.

\section{Romantic Creativity}

\section{Section 1. A rationale for a theoretical framework}

\subsection{Romantic relationships and wellbeing}

Wellbeing is a complex and dynamic construct that can be defined as the "balance point between an individual's resource pool and the challenges faced" (Dodge et al., 2012, p. 230). Although defining wellbeing has given rise to several difficulties (Diener, 2009; Hone et al., 2014; Huppert \& So, 2013; Keyes, 1998; Ryan \& Deci, 2001; Seligman, 2011), its various conceptualisations tend to find common ground in including: (a) engagement in daily activities; (b) a sense of purpose and meaning in life; and (c) positive relationships as pedestals of high-level wellbeing (Hone et al., 2014). Hence, positive romantic relationships are, by definition, embedded in the conceptualisation of wellbeing and its more dynamic, higher-level manifestation: human flourishing (e.g., Kemp et al., 2017).

\footnotetext{
${ }^{1}$ Hereafter, we define a dyad as a prolonged interaction between two individuals.
} 
Flourishing constitutes an important process in the long-term promotion of longevity. The GENIAL model proposed by Kemp and colleagues (2017) indicates how romantic relationships connect with high levels of wellbeing and highlights the importance of building positive social ties (i.e., high quality interpersonal relationships). It proposes that social relationships are a central aspect of human health from a life course perspective. Specifically, this model posits that positive social relationships interact with and influence moment-to-moment experiences, thus promoting healthy vagus nerve functions. In turn, the activation of the vagus nerve promotes positive health behaviours and wellbeing in an upwardly self-sustaining spiral. This line of research further argued that nourishing social relationships could offset the effects of many traditional risk factors, including smoking, alcohol consumption, and physical inactivity (Kemp et al., 2017). In this sense, positive social ties, such as romantic relationships, appear to importantly underpin the promotion of positive health outcomes.

Romantic relationships seem to constitute one of the most influential social bonds (e.g., Dush et al., 2008). A romantic (or intimate) relationship is a multifaceted construct that we can define as a mutual "state of intense longing for union with another" (Hatfield \& Sprecher, 1986, p. 383). The successful establishment and maintenance of a romantic relationship can have important effects in certain stages of life and can constitute a solid foundation upon which to build positive mental health and wellbeing (DeWall et al., 2011; Fincham \& Beach, 2010). More specifically, the quality of a romantic relationship appears to be one of the strongest predictors of an individual's wellbeing (Dush et al., 2008). Individuals with high quality spousal relations alongside the ability to engage in coping together as a unit tend to report high levels of wellbeing (Bodenmann et al., 2011). Other evidence shows that the higher the quality of their relationship, the more individuals report elevated levels of wellbeing (Chapman \& Guven, 2016). Similarly, relational stability longitudinally predicted better quality of life after 30 years of romantic relationships when compared to more erratic marriage trajectories (Roberson et al., 2018).

\subsection{Creativity and romantic relationships}

Creativity might play a role in fostering quality and/or stability in romantic relationships, thereby promoting dyadic wellbeing (Campbell \& Kaufman, 2017; Roberson et al., 2018; Strong \& Aron, 2006). However, to date, there has been no clear direct evidence on the extent to which such a claim is truly reliable. An early study by Paul Torrance found that, in comparison to lonesome creators, individuals who create as a dyad tend to report higher levels of originality, stimulation, and enjoyment (Torrance, 1970). Although modest, this seminal data suggested an association between dyadic creativity and wellbeing. Research developed subsequent experimental creative tasks in the hope that "couples... will be inspired to begin creating more positive, loving, and healthy interactions with one another and to achieve fulfilling goals together" (Sarnoff \& Sarnoff, 2005, p. 84). Yet, despite hinting at an interesting line of research, the effects of dyadic creativity on wellbeing have so far not been documented. Indeed, Torrance's paper has been cited fewer than 60 times as of July 2020, despite his otherwise highly influential status in the field of creativity research (e.g., Kim, 2006; Plucker, 1999; Zachopoulou et al., 2009). This suggests an initial timidity amongst researchers regarding dyadic creativity and romantic relationships.

Two main recent studies have advanced knowledge of the connection between creativity and romance. In the first one, Campbell and Kaufman (2017) explored "what makes a relationship last" (p. 3). Their cross-sectional data indicated that everyday creative behaviour, but not artistic behaviours, tends to predict passion, intimacy, and commitment in a couple. Furthermore, openness to experience - which, as a personality trait, is moderately and robustly associated with creativity (Feist, 1998; George \& Zhou, 2001; Silvia et al., 2009) - tends to correlate with passion 
and intimacy in men, while emotional stability tends to correlate with intimacy in women. In the second study, Carswell and colleagues addressed whether positive illusions about one's partner's physical appearance could predict passion, hypothesising that creativity could play a role in this relationship (Carswell et al., 2019). Their results indicated that individuals with high creativity-related personality traits and behaviours tend to find their partner especially attractive. Moreover, creativity appeared to moderate the decline of passion over time, suggesting that creativity connects to societally desirable aspects of human bonding.

These two studies are, to the best of our knowledge, the only ones that have at least partially considered the effects of creativity in romantic relationships. However, as we will now discuss, both studies contain assumptions that may limit understanding of the mechanisms of dyadic forms of creativity on wellbeing.

\subsection{Two assumptions about creativity in romantic relationships}

The first assumption contained in studies by Campbell and Kaufman (2017) and Carswell and colleagues (2019) relates to how the study of an individual perspective of romantic relationships has been taken as a reliable measure of the dyadic level. Prior research seems to have assumed that a measure of individual dimensions can be regarded as reliably corresponding to a measure of the functioning of a dyad. This consideration is apparent in the methodological choices, which fail to address how dyads can create together. Whether the research community has addressed creativity inside romantic relationships remains unclear. For instance, one study conceptualised creativity in romantic relationships through the lens of how one partner perceives the other (Carswell et al., 2019), while the other study addressed how individual creativity predicts the self-reported perception that a partner has of their relationship with their partner (Campbell \& Kaufman, 2017).

In summary, research centred on the relationship between creativity and romantic relationships has, thus far, assumed that such a link can be validly addressed by only focusing on one part of the dyad. To date, no research has considered the functioning of the dyad as a single unit consisting of two closely interacting parts. For instance, a series of studies conducted by Carswell and colleagues (2019), including a 9-month longitudinal project with dyads, restricted its scope with respect of creativity in romantic relationships to the study of two individual aspects rather than proper dyadic connections. Indeed, the authors chose not to compute interaction effects as (Partner A x Partner B) scores. Yet, such a procedure could be more relevant to theoretically represent dyadic interactive functioning.

The second assumption relates to how these studies have sought to use creativity to buffer specifically against a decline in relationship length. The idea that creativity could act as a way to prevent a decline in passion is grounded in the notion that passion is connected to wellbeing (Carswell et al., 2019, p. 4). Briefly, this view assumes the importance of preventing boredom as a cause of decline of passion, which may threaten marriage as an act of faith and a religious engagement (Carswell et al., 2019, p. 5). This assumption is also apparent in Campbell and Kaufman (2017) who state: "Given that relationships tend to dissolve once love fades... partners must continually find ways to sustain it" (p. 22). Likewise, Carswell and colleagues (2019, p. 6) "hoped to identify a novel predictor of individuals' ability to maintain romantic passion". The assumption that creativity research should help in exploring how to foster relationship longevity is indeed critical. Yet, this view tends also to imply that relationship length is more important than relationship quality. Research, however, has confirmed that long relationships with conflicts are possible, and that relationship quality and relationship satisfaction are the most significant factors in romantic relationships (Chapman \& Guven, 2016; Muise et al., 2019). Consequently, 
we need to consider with more nuance how creativity may foster longer relationships and/or promote relationship quality.

We are therefore confronted by at least two main assumptions, each of which has consequences. The first concerns the past practice of measuring separate individual levels in a relationship (what we may call two "monads") which, with no computation of interactions, cannot be claimed to reliably measure creativity at a dyadic level. The second centres on the idea that it is crucial to maintain passion and relationship length. Regarding the effects of dyadic creativity in romantic relationship on wellbeing, these two assumptions provide no answer to the following questions: How do partners influence each other to produce something new? What are the effects of dyadic creativity on both partners' wellbeing? What are the underlying dynamics and processes of this phenomenon? These questions remain open. To some extent, this is unfortunate. As Forgeard and Kaufman (2016) pointed out, contemporary research knows little about the benefits of creativity on health and wellbeing, let alone the effect of dyadic creativity on wellbeing. Thus, to advance on these considerations, the field needs a complementary theoretical framework to address creativity in romantic relationships and its effects on wellbeing.

\section{Section 2. The epistemological foundations of the romantic creativity framework}

The studies discussed above have helped to identify research on creativity and romantic relationships in connection with wellbeing and their assumptions. In this second section, we articulate new and complementary assumptions and epistemological foundations of what we call "the romantic creativity framework". We articulate romantic creativity through the following definition:

Romantic creativity is a dyadic process which favours new and meaningful directions in a romantic relationship through dynamics of discovery and self-expansion in one or both members of the dyad.

Thus, the framework proposes that a dyad contributes in one or both partners to the exploration of new geographical territories (e.g., deciding to move to a new country together), to spiritual development (e.g., jointly discovering the appeal of a novel way of approaching life), to intellectual growth (e.g., deciding to pursue a type of scientific inquiry that they had not considered before), or behavioural change (e.g., jointly changing habits).

\subsection{Examples of Romantic Creativity and underlying assumptions}

The romantic creativity framework adopts two main assumptions that complement those already highlighted above. First, it proposes that the dyadic phenomenon is not reducible to the sum of its parts and, importantly, that scientific inquiries about dyads require researchers to approach two romantic partners as a single unit of study. Pinto (2017, p. 580) placed a similar emphasis on the romantic couple. She proposed to go beyond the focus on the individual characteristics of partners by studying how the romantic couple operates, how each member influences the other's life, and how their romantic relationship's functioning influences - and is influenced by - sociocultural and political contexts. Drawing from Pinto's work, we can approach romantic creativity as a fundamentally dynamic, and systemic construct. Second, while previous research has assumed that creativity should maintain passion, romantic creativity posits that romantic relationships flourish through movement and expansion, and that a decline in passion represents a specific case of relational dynamics (Aron et al., 1998). The maintenance of passion is 
approached as a corollary, but not as the end goal, of how romantic partners engage in dyadic, self-expanding, meaningful experiences.

The romantic creativity framework engages with subsequent assumptions. Romantic creativity defines a construct that is both observable and quantifiable. Its observable and quantifiable features refer to what can be expected from classical constructs in the psychology of creativity: research can measure romantic creativity through self-reported questionnaires, behavioural responses, and other standard quantitative and qualitative methodologies. For instance, Campbell and Kaufman (2017) recommended that counsellors "encourage partners adopt more creative practices into their everyday life such as trying a new recipe, starting a hobby together, and finding unique ways to communicate love. Such practices may help strengthen the relationship and avoid dissolution" (p. 22). Romantic creativity could be particularly (but not exclusively) observable and quantifiable through such activities.

Furthermore, it is likely to observe and measure romantic creativity when (a) the dyad engages in shared activities (e.g., starting a new hobby together) which (b) foster meaningful new life directions in one or both members of the dyad. In other words, the activities proposed by Campbell and Kaufman may not inherently reflect a manifestation of romantic creativity. For instance, learning a new language with one's partner may not be seen as a form of romantic creativity. Conversely, an example of romantic creativity could be a scenario where partners decide to learn a specific language together and discover that they would love to visit the targetlanguage speaking country together. In that case, the activity itself is not inherently romantically creative; rather, it is the fact that the two partners together discover new and meaningful directions/insights in their lives that is deemed romantically creative (e.g., Beghetto \& Kaufman, 2007). Another example could relate to specific activities, where one partner invites the other to participate together, say, in a triathlon, skydiving, or spending a weekend fishing, dancing, or meditating. This activity could be defined as a romantic creative activity, as long as the activity: (a) engaged the two partners in a process of trying and discovering things (not necessarily new things); (b) was perceived by one or both members of the dyad as meaningful; and (c) focused them on a novel direction in their life together.

Furthermore, we propose that the romantic creativity framework can be appraised in the light of how partners co-construct the narrative of their love story. Indeed, how people envisage and tell their own romances, both as individuals and as a dyad, can be regarded as a creative endeavour. This is, of course, context specific and underpinned by questions relating to how and why people arrange memories and experiences to create the tale of their romantic relationship. We could expect that partners would idealise the narrative they build, both individually and at a dyadic level, in the same way that individuals with high creativity-related personality traits tend to have positive illusions about their partner (Carswell et al., 2019). It would be interesting to address the extent to which these illusions are dependent upon both partners. ${ }^{2}$

The core of the definition of romantic creativity implies the dyadic progression of novel directions in life. This aspect can be measured using self-reported questionnaires. For instance, we would measure how dyads perceive their experiences as promoting a need to pursue something new, create new habits or new desires, or how an experience has changed or is changing their worldview, part of their personalities, or outlook towards a specific task/activity. Thus, romantic creativity can be approached as a prolonged meaningful experience, or as an ongoing process that evolves throughout a romantic relationship. This assumption may imply

\footnotetext{
${ }^{2}$ For instance, this idealisation may show adaptive purposes and foster coping in the face of adversity. Indeed, it has been shown that among widowed individuals, the individual's creation of a positive narrative about their relationship with their partner fostered their coping abilities (Barusch, 2008, p. 119).
} 
moment-to-moment measurement methods. For instance, experience sampling or Interpretative Phenomenological Analysis may be suitable methods for studying the dynamics of romantic creativity (e.g., Graham, 2008; Smith \& Osborn, 2003).

It is important to emphasise that the activity in question would not have to be novel; rather, it is the perception of how the activity has transformed one or both partners that is likely to matter. Indeed, we expect that some meaningful insights could occur through time spent engaging in an activity that is not "novel". Therefore, a focus on what is produced, and on how external social groups evaluate the activity according to social standards and comparisons, are of little relevance to the romantic creativity framework. Instead, what is important is that one or both partners perceive that the experience was meaningful, and that it moved them in novel directions in their life together.

Given that the proposed concept of romantic creativity frames dyadic self-expansion and personal insights, social evaluation could lack relevance in romantic creativity. Hence, as a third epistemological assumption, romantic creativity could refer to a "non-product-hierarchic" phenomenon. In that sense, we can consider the romantic creativity framework in relation to the four-c model of creativity (Kaufman \& Beghetto, 2009). The four-c model structures creativity alongside a continuum which classifies and creates a hierarchy of individual achievements ranging from everyday accomplishments to eminent outputs. Through this lens, the four-c model does not to truly match the epistemological stance of the romantic creativity framework. Indeed, by positioning eminent productions as the higher levels of its framework, this four-c model emphasises the importance of producing original and recognised products specific creative domains. The romantic creativity framework, on the other hand, addresses how a shared activity and/or a shared experience creates a bifurcation in the way one or both partners perceive their worldviews, act in their lives, or discover and expand themselves through new experiences, and interests. Romantic creativity refers fundamentally to intra-individual insights and changes. Thus, essentially, it would connect to the first stratum of the model: mini-c (Beghetto \& Kaufman, 2007).

\subsection{Romantic creativity, self-expansion, and ontologies}

We have proposed that romantic creativity is concerned with how a dyad can move in novel directions, and self-expand ${ }^{3}$ (Aron et al., 1998; Strong \& Aron, 2006). Accordingly, the selfexpansion model assumes that individuals have a desire to self-expand both in and outside their romantic relationship, and to search for new stimuli (Aron et al., 1998, 2013). Individuals seek such growth to improve their efficacy and develop new self-concepts. That is, they search to develop new parts of their identity through challenging, arousing, and novel activity (e.g., Reissman et al., 1993). Self-expansion theory claims that relationships shape our identity and help us to gain access to new types of resources (e.g., new friends through our partner's social network; new materials when partners cohabit together; more money) or new types of activities (e.g., one partner helping the other to discover new interests, such as classical music, bricolage skills, or eco-friendly everyday behaviours).

\footnotetext{
${ }^{3}$ The conceptual framework of romantic creativity draws on research and theories of self-expansion (Aron et al., 1998, 2013). A logical question to ask here is how the present framework can contribute to understanding of the self-expansion theory. It is worth stressing that the conceptual framework of romantic creativity is not a replica of the self-expansion model. First, romantic creativity proposes that this mechanism may occur through homeodynamics, something which is not proposed by the self-expansion model. Romantic creativity may even complement self-expansion research to that extent. A second aspect prevents romantic creativity from being a mere replica of the self-expansion model, as romantic creativity is about how dyadic functioning influences each part of the dyad, and how partners grow together through the discovery of a novel life direction. This conceptualisation is not approached in the self-expansion model.
} 
The proposed romantic creativity framework, and its assumed association with selfexpansion, can be contextualised in relation to Drigotas et al's (1999) Michelangelo Phenomenon and its ontology which connect to wellbeing (Drigotas, 2002; Rusbult et al., 2009). The Michelangelo Phenomenon is a concept that frames how individuals influence, foster, or hinder each partner's goals of individualisation. In other words, each partner's self-expansion is encouraged through their interpersonal experiences and is posited to allow them to attain their "ideal self" (Rusbult et al., 2009, p. 306). In this model, each partner contributes to help the other to get closer to their "ideal self", and thus to account for their individual and dyadic wellbeing (Drigotas, 2002). Conversely, if a partner were to move away from their "ideal self", this would cause a diminution of both individual and dyadic wellbeing. In our understanding, this model implies a Platonist ontology (Balaguer, 2016) which assumes an idealist, achievable view worthy of pursual. This view constitutes one possible ontology within which to frame research on romantic creativity.

As a second ontological standpoint which merits further research, romantic creativity can be approached through Duymedjian and Rüling's (2010) discussion of anthropologist Lévi-Strauss's (1994) ontology of bricolage. In their conceptual paper, Duymedjian and Rüling distinguished between bricoleur and ingénieur. Briefly, "ingénieur" engages in an idealised ontology - similar to the Michelangelo Phenomenon - whereas the "bricoleur" does not. The bricoleur's ontology accounts for wellbeing, not through idealising goals, objectives, and tasks, but via an exploration, an inventory, and a subtle understanding of their environment, which always provides sufficient means for a partly indeterminate end. Lévi-Strauss (1994) importantly cites Reichard in saying that "...the Navajo [Native American] regard all parts of the universe as essential to wellbeing" (p. 46). The logical argument of this ontology is as follows: if all parts of nature are essential to wellbeing, then idealisation and hierarchies are not relevant to wellbeing. Indeed, everything is then assumed to bring something important to the bricoleur's arrangement and flourishing. Thus, as an alternative to the Michelangelo Phenomenon's ontology, romantic creativity may also be addressed as the extent to which dyadic romantic activities can help each partner to discover new aspects of themselves. In other words, such an ontology frames how romantic creativity may foster gains in a stable and clear self-concept that has the power to contribute to partners' wellbeing (for research on self-concept and wellbeing see, for instance, Ritchie et al., 2011; Usborne \& Taylor, 2010).

Although we propose a conceptualisation of dyadic romantic creativity as an avenue for dyadic self-expansion, we temper this claim with the view proposed by Cancian's (1987) work that 1950s liberalism and individuals' emancipation led to an impoverishment of commitment in close relationships. Consequently, and specifically in American culture, it appears that the support acquired from one's intimate partner is often viewed as crucial to attaining the desired individualisation and self-realisation. This claim can also be found in the Michelangelo Phenomenon, wherein partners become the "sculptors" of their partner's selves (Drigotas, 2002; Drigotas et al., 1999). In this way, Cancian emphasised how American culture tends to instrumentalise love to pursue individualistic self-expansion goals. Therefore, we argue here that the study of how romantic relationships create and self-expand together is subject to the varied, perhaps conflicting, ontological perspectives held in different cultures. Hence, further research could want to focus on romantic partners' ontologies to address the following questions: do dyads self-expand in shared experiences with an idealised view of themselves? Conversely, do romantic relationships allow partners to engage in dyadic self-expansion in novel directions without predefined schemes? In which circumstances do dyads gain which benefits and at what cost? In this sense, cross-cultural research may offer relevant research perspectives. 


\subsection{Romantic creativity and neuroscientific assumptions}

Homeostasis, and its more dynamic form, "homeodynamics", may offer neuroscientific support to the romantic creativity framework. In its initial conceptualisation, homeostasis refers to a process that helps organisms maintain and return to a stable internal state (Cannon \& Cannon, 1932/1967). More recent work, discussed below, has proposed to extend the steady-state aspect of homeostasis to a more dynamic one.

Steady states are often not associated with wellbeing. For instance, a complete state of equilibrium is equivalent to the concept of entropy, which provokes anxious states in humans, and is thus in opposition to a concept of wellbeing (Dodge et al., 2012; Hirsh et al., 2012). Conversely, depressive states, which are also opposed to wellbeing, are often treated with the support of "behavioural activation" procedures. Behavioural activation engages the person in tasks that are designed to push them towards accomplishing actions, and which set them in motion to reduce their depressive symptoms as a first step toward recovery and wellbeing (Ekers et al., 2014). Therefore, the mechanisms of romantic creativity mobilise homeodynamic rather than homeostatic processes, putting the individual into motion.

Lloyd et al. (2001) used the concept of homeodynamics to describe self-organised structures (e.g., an individual mind, or a romantic relationship) which exhibit both fixed set points, as in classical homeostasis, while also involving more dynamic processes. More specifically, the concept of homeodynamics is defined as a series of "bifurcation points" that compel an organism to lose stability to foster behavioural quantitative or qualitative changes (e.g., Lloyd et al., 2001, p. 136). The work of neuroscientist Antonio Damasio has shown that, within an optimal range, homeodynamics are experienced by individuals as feelings of joy, happiness, and wellbeing where their close relationships (e.g., romantic relationships) contribute efficiently to meeting their homeostatic/homeodynamic needs and fostering their health (e.g., Damasio, 2018, p. 117; see also Kemp et al., 2017). While it was proposed above that romantic creativity refers to how an activity creates changes and bifurcation in the dyad, it may be expected that this bifurcation reflects the qualitative and quantitative changes required for homeodynamic flourishing.

This line of research might partly explain why excitement, fun, or surprise often buffer against the diminution of a partner's perception of the positive quality of their relationship, and foster satisfaction in romantic relationships (Aron et al., 1998, 2013; Harasymchuk \& Fehr, 2013; Reissman et al., 1993; Strong \& Aron, 2006). It is possible that the sharing of some dyadic activities in the romantic relationship may promote flourishing as these activities can be perceived as surprising and exciting, and may thus be identified as a potential source of expansion by the dyad (Damasio, 2018; Malouff et al., 2015). Indeed, evidence shows that romantic relationships that engage in self-expansion via novel activities heighten the partners' satisfaction in their relationship over time (Muise et al., 2019).

\section{Section 3. Summary, contributions, and future directions}

\subsection{Overview of the romantic creativity framework}

Figure 1 integrates and summarises the theoretical framework of romantic creativity. Romantic creativity is rooted in wellbeing and its higher level, flourishing, through at least two aspects: (a) a dyadic process that fosters positive social ties (Kemp et al., 2017); and (b) a dynamic phenomenon of self-expansion that might reflect homeodynamic mechanisms, and encourage enjoyment and flourishing in dyads through self-expansion (Aron et al., 2013; Damasio, 2018; Lloyd et al., 2001). It is hoped that this framework will build understanding of the benefits of creativity for wellbeing at a dyadic level, and that it will complement previous research on how creativity is embedded in romantic relationships (Campbell \& Kaufman, 2017; Carswell et al., 
2019). Romantic creativity may thus provide an ontological and epistemological foundation for measuring dyadic function through moment-to-moment interactions, and address how these nurture flourishing.

The theoretical framework of romantic creativity proposes that the co-construction of novel and meaningful experiences that foster the self-expansion and unfamiliar life directions of the dyad might occur through homeodynamic bifurcation, as conceptualised by Lloyd and colleagues (2001). In that sense, we could expect the positive effects of such bifurcation (e.g., how the creation of a novel experience in the dyad fosters a bifurcation of the dyad's life direction) to be under the influence of the mechanisms that conserve each dyadic member's alterity. We can define alterity as the quality of otherness that is opposite to, distinct from, or inassimilable by, the self. As such, it is the opposite of identity or sameness (Huett \& Goodman, 2014). We could predict that for a dyadic activity to be able to foster bifurcation in one of the two partners, Partner A would need to be sufficiently different from Partner B to propose an activity or an experience that may bring about change in Partner B. Essentially, alterity might be seen as a condition of exploration and exploitation of one's partner's resources, in a way which promotes wellbeing, according to its definition (Dodge et al., 2012, p. 230).

Conversely, we could hypothesise that for this alterity to take place, partners would need to share important domains of similarity. Indeed, prior research shows that comparable backgrounds, attitudes, and leisure choices predict attraction between partners (Byrne et al., 1970; Sprecher \& Regan, 2002). Some evidence suggests that when individuals seek long term relationships, similarity is mostly desire in terms of career goals, food preferences, travel desires, and music taste (Treger \& Masciale, 2018). Furthermore, perceived affinities, rather than actual and objective close equivalences, tend to predict attraction (Montoya et al., 2008; Sprecher et al., 2015). Sprecher et al. (2015) found that self-expansion mediated the relationship between perceived similarity and attraction. When participants welcomed dissimilarity (i.e., "to have alterity in"), it concerned domains such as playing sports/athletics, political activities and interests, and academic pursuits. This line of research connects with previous work on selfexpansion. This line of research showed that individuals who are primed towards self-expansion tend to be more likely to be attracted by partners who are to a large extend similar to them in main aspects of their self-concept (Aron et al., 2006, 2013). Thus, future research could explore how quantitative similarities may act as a moderator in romantic relationships, and whether qualitative dissimilarities in a domain where partners share general similarities could moderate the relationship between dyadic creative experiences and self-expansion. 


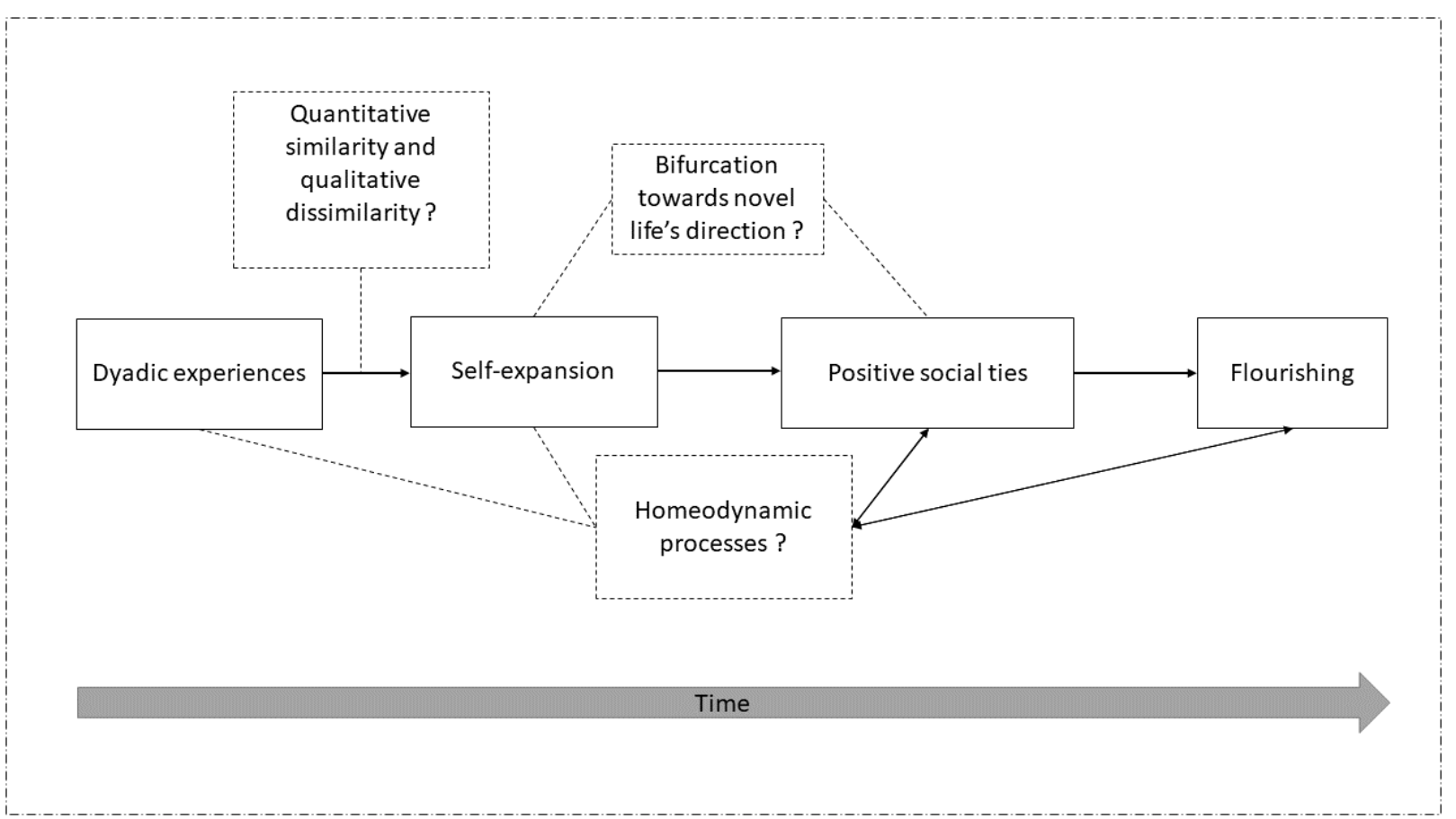

Figure 1. A theoretical framework of Romantic Creativity

Note. Dyadic experiences imply new perceptions and insights. Although the dyadic activities themselves do not necessarily have to be novel, the bifurcations in partners' lives are. The present illustration focuses exclusively on flourishing. Yet, we do not reject the hypothesis that dyadic creativity experiences may restrain or hinder one partner, thus potentially resulting in negative social ties, depression, and/or associated psychopathology. Proposed relationships supported by empirical evidence are highlighted in bold. More hypothetical paths are presented in dotted lines and boxes. These variables require more empirical research to address the falsifiability of this model.

\subsection{Conclusion}

While the framework is based on empirical work on self-expansion and neuroscientific approaches, important aspects of the view of romantic creativity remain flexible and open to future criticism and adjustments. The neuroscientific and neurobiological foundations upon which the romantic creativity framework is based offer a reliable basis for the development of romantic creativity (Damasio, 2018; Kemp et al., 2017; Lloyd et al., 2001). Further research is needed to address whether and/or how homeodynamic processes are at play, and whether they explain the effect of romantic creativity on flourishing. Likewise, we have proposed some methodological perspectives on how to quantify and qualify romantic creativity, which aim to explore the relevance of moment-to-moment approaches to the study of romantic creativity. Another avenue for additional research lies in the ontological perspectives of the romantic creativity framework: are individuals engaging in romantic creativity to serve an idealised view of themselves? Or, do they have a more open-ended ontology that serves their wellbeing and quality of romantic relationships? Thus, we have proposed a non-definitive view of what it might mean to be "creative" in a romantic relationship, and what the manifestations of such a "romantic creativity" might be. How and when could romantic creativity and wellbeing be further nourished in dyads, and from which ontological standpoint? What motivates partners to foster growth in their relationship? How do partners report how their relationship has changed their 
life trajectory, and under what circumstances, at what cost, and for what benefits? These central aspects of romantic creativity are all wide open for investigation. They can serve to address the limitations and areas requiring improvement of the present theoretical framework of romantic creativity.

\section{Acknowledgements}

We are grateful to Jane Guiller, Andrew H. Kemp, Kareena McAloney-Kocaman, Dominique Steiler, Julie Thomson, Agata Urbanowicz, and Katia Zhuk for their insightful ideas, guidance, and support throughout the process of preparing and writing this article. We also thank Colin Cumming for his diligent proofreading work and the two anonymous reviewers whose feedback helped to improve the manuscript.

\section{Conflict of interest statement}

The authors report no conflicts of interest.

\section{Authors}

Nicolas B. Verger

Glasgow Caledonian University

Raffi Duymedjian

Grenoble School of Management

\section{Publishing Timeline}

Received 2 September 2020

Accepted 26 November 2020

Published 17 December 2020

\section{References}

Amabile, T. M. (1982). Social psychology of creativity: A consensual assessment technique. Journal of Personality and Social Psychology, 43(5), 997-1013. https://doi.org/10.1037/0022-3514.43.5.997

Aron, A., Lewandowski Jr., G. W., Mashek, D., \& Aron, E. N. (2013). The self-expansion model of motivation and cognition in close relationships. In J. Simpson \& L. Campbell (Eds.), The Oxford handbook of close relationships (pp. 90-115). Oxford University Press.

Aron, A., Norman, C. C., \& Aron, E. N. (1998). The self-expansion model and motivation. Representative Research in Social Psychology, 22, 1-13.

Aron, A., Steele, J. L., Kashdan, T. B., \& Perez, M. (2006). When similars do not attract: Tests of a prediction from the self-expansion model. Personal Relationships, 13(4), 387-396. https://doi.org/10.1111/j.1475-6811.2006.00125.x

Balaguer, M. (2016). Platonism in metaphysics. In E. N. Zalta (Ed.), The Stanford encyclopedia of philosophy Stanford University. https://plato.stanford.edu/archives/spr2016/entries/platonism/

Barusch, A. S. (2008). Love stories of later life: A narrative approach to understanding romance. Oxford University Press.

Beghetto, R. A., \& Kaufman, J. C. (2007). Toward a broader conception of creativity: A case for 'mini-c' creativity. Psychology of Aesthetics, Creativity, and the Arts, 1(2), 73-79. https://doi.org/10.1037/19313896.1.2.73

Bodenmann, G., Meuwly, N., \& Kayser, K. (2011). Two conceptualizations of dyadic coping and their potential for predicting relationship quality and individual well-being: A comparison. European Psychologist, 16(4), 255-266. https://doi.org/10.1027/1016-9040/a000068

Byrne, D., Ervin, C. R., \& Lamberth, J. (1970). Continuity between the experimental study of attraction and real-life computer dating. Journal of Personality and Social Psychology, 16(1), 157-165.

https://doi.org/10.1037/h0029836 
Campbell, K., \& Kaufman, J. (2017). Do you pursue your heart or your art? Creativity, personality, and love. Journal of Family Issues, 38(3), 287-311. https://doi.org/10.1177/0192513X15570318

Cancian, F. (1987). Love in America: Gender and self-development. Cambridge University Press.

Cannon, W. B., \& Cannon, C. J. (1967). The wisdom of the body: How the human body reacts to disturbance and danger and maintains the stability essential to life (Rev. ed.). Norton.

Carroll, R. (2005). Finding the words to say it: The healing power of poetry. Evidence-Based Complementary and Alternative Medicine, 2(2), 161-172. https://doi.org/10.1093/ecam/neh096

Carswell, K. L., Finkel, E. J., \& Kumashiro, M. (2019). Creativity and romantic passion. Journal of Personality and Social Psychology, 116(6), 919-941. https://doi.org/10.1037/pspi0000162

Chapman, B., \& Guven, C. (2016). Revisiting the relationship between marriage and wellbeing: Does marriage quality matter? Journal of Happiness Studies, 17(2), 533-551. https://doi.org/10.1007/s10902014-9607-3

Conner, T. S., DeYoung, C. G., \& Silvia, P. J. (2018). Everyday creative activity as a path to flourishing. The Journal of Positive Psychology, 13(2), 181-189. https://doi.org/10.1080/17439760.2016.1257049

Conner, T. S., \& Silvia, P. J. (2015). Creative days: A daily diary study of emotion, personality, and everyday creativity. Psychology of Aesthetics, Creativity, and the Arts, 9(4), 463-470. https://doi.org/10.1037/aca0000022

Csikszentmihalyi, M. (1988). The flow experience and its significance for human psychology. In M. Csikszentmihalyi \& I. S. Csikszentmihalyi (Eds.), Optimal experience (pp. 15-35). Cambridge University Press. https://doi.org/10.1017/CBO9780511621956.002

Csikszentmihalyi, M. (1990). Flow: The psychology of optimal experience. Harper \& Row.

Damasio, A. R. (2018). The strange order of things: Life, feeling, and the making of the cultures. Pantheon Books.

Darewych, O. H., \& Riedel Bowers, N. (2018). Positive arts interventions: Creative clinical tools promoting psychological well-being. International Journal of Art Therapy, 23(2), 62-69. https://doi.org/10.1080/17454832.2017.1378241

DeWall, C. N., Maner, J. K., Deckman, T., \& Rouby, D. A. (2011). Forbidden fruit: Inattention to attractive alternatives provokes implicit relationship reactance. Journal of Personality and Social Psychology, 100(4), 621-629. https://doi.org/10.1037/a0021749

Diener, E. (Ed.). (2009). Culture and well-being (Vol. 38). Springer. https://doi.org/10.1007/978-90-481-23520

Dodge, R., Daly, A., Huyton, J., \& Sanders, L. (2012). The challenge of defining wellbeing. International Journal of Wellbeing, 2(3), 222-235. https://doi.org/10.5502/ijw.v2i3.4

Drigotas, S. M. (2002). The Michelangelo Phenomenon and personal well-being. Journal of Personality, 70(1), 59-77. https://doi.org/10.1111/1467-6494.00178

Drigotas, S. M., Rusbult, C. E., Wieselquist, J., \& Whitton, S. W. (1999). Close partner as sculptor of the ideal self: Behavioral affirmation and the Michelangelo Phenomenon. Journal of Personality and Social Psychology, 77(2), 293-323. https://doi.org/10.1037/0022-3514.77.2.293

Dush, C. M. K., Taylor, M. G., \& Kroeger, R. A. (2008). Marital happiness and psychological well-being across the life course. Family Relations, 57(2), 211-226. https://doi.org/10.1111/j.1741-3729.2008.00495.x

Duymedjian, R., \& Rüling, C.-C. (2010). Towards a foundation of bricolage in organization and management theory. Organization Studies, 31(2), 133-151. https://doi.org/10.1177/0170840609347051

Ekers, D., Webster, L., Straten, A. V., Cuijpers, P., Richards, D., \& Gilbody, S. (2014). Behavioural activation for depression; An update of meta-analysis of effectiveness and sub group analysis. PLoS ONE, 9(6), e100100. https://doi.org/10.1371/journal.pone.0100100

Feist, G. J. (1998). A meta-analysis of personality in scientific and artistic creativity. Personality and Social Psychology Review, 2(4), 290-309. https://doi.org/10.1207/s15327957pspr0204_5

Fincham, F. D., \& Beach, S. R. H. (2010). Marriage in the new millennium: A decade in review. Journal of Marriage and Family, 72(3), 630-649. https://doi.org/10.1111/j.1741-3737.2010.00722.x

Forgeard, M. J. C., \& Elstein, J. G. (2014). Advancing the clinical science of creativity. Frontiers in Psychology, 5, 613. https://doi.org/10.3389/fpsyg.2014.00613 
Forgeard, M. J. C., \& Kaufman, J. C. (2016). Who cares about imagination, creativity, and innovation, and why? A review. Psychology of Aesthetics, Creativity, and the Arts, 10(3), 250-269. https://doi.org/10.1037/aca0000042

George, J. M., \& Zhou, J. (2001). When openness to experience and conscientiousness are related to creative behavior: An interactional approach. Journal of Applied Psychology, 86(3), 513-524. https://doi.org/10.1037/0021-9010.86.3.513

Graham, J. M. (2008). Self-expansion and flow in couples' momentary experiences: An experience sampling study. Journal of Personality and Social Psychology, 95(3), 679-694. https://doi.org/10.1037/0022-3514.95.3.679

Harasymchuk, C., \& Fehr, B. (2013). A prototype analysis of relational boredom. Journal of Social and Personal Relationships, 30(5), 627-646. https://doi.org/10.1177/0265407512464483

Hatfield, E., \& Sprecher, S. (1986). Measuring passionate love in intimate relationships. Journal of Adolescence, 9(4), 383-410. https://doi.org/10.1016/S0140-1971(86)80043-4

Hirsh, J. B., Mar, R. A., \& Peterson, J. B. (2012). Psychological entropy: A framework for understanding uncertainty-related anxiety. Psychological Review, 119(2), 304-320. https://doi.org/10.1037/a0026767

Hone, L. C., Jarden, A., Schofield, G., \& Duncan, S. (2014). Measuring flourishing: The impact of operational definitions on the prevalence of high levels of wellbeing. International Journal of Wellbeing, 4(1), 62-90. https://doi.org/10.5502/ijw.v4i1.4

Huett, S., \& Goodman, D. (2014). Alterity. In T. Teo (Ed.), Encyclopedia of critical psychology (pp. 82-87). Springer. https://doi.org/10.1007/978-1-4614-5583-7_13

Huppert, F. A., \& So, T. T. C. (2013). Erratum to: Flourishing across Europe: Application of a new conceptual framework for defining well-being. Social Indicators Research, 110(3), 1245-1246. https://doi.org/10.1007/s11205-012-0030-z

Kaufman, J. C., \& Beghetto, R. A. (2009). Beyond big and little: The four c model of creativity. Review of General Psychology, 13(1), 1-12. https://doi.org/10.1037/a0013688

Kemp, A. H., Arias, J. A., \& Fisher, Z. (2017). Social ties, health and wellbeing: A literature review and model. In A. Ibáñez, L. Sedeño, \& A. M. García (Eds.), Neuroscience and social science (pp. 397-427). Springer International Publishing. https://doi.org/10.1007/978-3-319-68421-5_17

Keyes, C. L. M. (1998). Social well-being. Social Psychology Quarterly, 61(2), 121. https://doi.org/10.2307/2787065

Kim, K. H. (2006). Can we trust creativity tests? A review of the Torrance Tests of Creative Thinking (TTCT). Creativity Research Journal, 18(1), 3-14. https://doi.org/10.1207/s15326934crj1801_2

Levi-Strauss, C. (1994). The Savage Mind. Weidenfeld \& Nicolson.

Lloyd, D., Aon, M. A., \& Cortassa, S. (2001). Why homeodynamics, not homeostasis? The Scientific World Journal, 1, 133-145. https://doi.org/10.1100/tsw.2001.20

Malouff, J. M., Mundy, S. A., Galea, T. R., \& Bothma, V. N. (2015). Preliminary findings supporting a new model of how couples maintain excitement in romantic relationships. The American Journal of Family Therapy, 43(3), 227-237. https://doi.org/10.1080/01926187.2015.1034634

Maslow, A. H. (1958). A dynamic theory of human motivation. In C. L. Stacey \& M. DeMartino (Eds.), Understanding human motivation (pp. 26-47). Howard Allen Publishers. https://doi.org/10.1037/11305004

Montoya, R. M., Horton, R. S., \& Kirchner, J. (2008). Is actual similarity necessary for attraction? A metaanalysis of actual and perceived similarity. Journal of Social and Personal Relationships, 25(6), 889-922. https://doi.org/10.1177/0265407508096700

Muise, A., Harasymchuk, C., Day, L. C., Bacev-Giles, C., Gere, J., \& Impett, E. A. (2019). Broadening your horizons: Self-expanding activities promote desire and satisfaction in established romantic relationships. Journal of Personality and Social Psychology, 116(2), 237-258. https://doi.org/10.1037/pspi0000148

Pennebaker, J. W. (1997). Writing about emotional experiences as a therapeutic process. Psychological Science, 8(3), 162-166. https://doi.org/10.1111/j.1467-9280.1997.tb00403.x

Pinto, S. (2017). Researching romantic love. Rethinking History, 21(4), 567-585. https://doi.org/10.1080/13642529.2017.1333288 
Plucker, J. A. (1999). Is the proof in the pudding? Reanalyses of Torrance's (1958 to present) longitudinal data. Creativity Research Journal, 12(2), 103-114. https://doi.org/10.1207/s15326934crj1202_3

Plucker, J. A., Beghetto, R. A., \& Dow, G. T. (2004). Why isn't creativity more important to educational psychologists? Potentials, pitfalls, and future directions in creativity research. Educational Psychologist, 39(2), 83-96. https://doi.org/10.1207/s15326985ep3902_1

Potash, J. S., Ho, A. H., Chan, F., Wang, X. L., \& Cheng, C. (2014). Can art therapy reduce death anxiety and burnout in end-of-life care workers? A quasi-experimental study. International Journal of Palliative Nursing, 20(5), 233-240. https://doi.org/10.12968/ijpn.2014.20.5.233

Reissman, C., Aron, A., \& Bergen, M. R. (1993). Shared activities and marital satisfaction: Causal direction and self-expansion versus boredom. Journal of Social and Personal Relationships, 10(2), 243254. https://doi.org/10.1177/026540759301000205

Richards, R. (2010). Everyday creativity. In J. C. Kaufman \& R. J. Sternberg (Eds.), The Cambridge handbook of creativity (pp. 189-215). Cambridge University Press.

https://doi.org/10.1017/CBO9780511763205.013

Richardson, P., Jones, K., Evans, C., Stevens, P., \& Rowe, A. (2007). Exploratory RCT of art therapy as an adjunctive treatment in schizophrenia. Journal of Mental Health, 16(4), 483-491.

https://doi.org/10.1080/09638230701483111

Ritchie, T. D., Sedikides, C., Wildschut, T., Arndt, J., \& Gidron, Y. (2011). Self-concept clarity mediates the relation between stress and subjective well-being. Self and Identity, 10(4), 493-508. https://doi.org/10.1080/15298868.2010.493066

Roberson, P. N. E., Norona, J. C., Lenger, K. A., \& Olmstead, S. B. (2018). How do relationship stability and quality affect wellbeing?: Romantic relationship trajectories, depressive symptoms, and life satisfaction across 30 years. Journal of Child and Family Studies, 27(7), 2171-2184. https://doi.org/10.1007/s10826-018-1052-1

Runco, M. A., \& Jaeger, G. J. (2012). The standard definition of creativity. Creativity Research Journal, 24(1), 92-96. https://doi.org/10.1080/10400419.2012.650092

Rusbult, C. E., Finkel, E. J., \& Kumashiro, M. (2009). The Michelangelo Phenomenon. Current Directions in Psychological Science, 18(6), 305-309. https://doi.org/10.1111/j.1467-8721.2009.01657.x

Ryan, R. M., \& Deci, E. L. (2001). On happiness and human potentials: A review of research on hedonic and eudaimonic well-being. Annual Review of Psychology, 52(1), 141-166. https://doi.org/10.1146/annurev.psych.52.1.141

Sarnoff, D. P., \& Sarnoff, P. (2005). Assessing interactive creativity in couples. The Family Journal, 13(1), 83-86. https://doi.org/10.1177/1066480704270227

Seligman, M. (2011). Flourish: A new understanding of happiness and well-being, and how to achieve them. Brealey Publishing.

Silvia, P. J., Nusbaum, E. C., Berg, C., Martin, C., \& O'Connor, A. (2009). Openness to experience, plasticity, and creativity: Exploring lower-order, high-order, and interactive effects. Journal of Research in Personality, 43(6), 1087-1090. https://doi.org/10.1016/j.jrp.2009.04.015

Smith, J. A., \& Osborn, M. (2003). Interpretative phenomenological analysis. In J.A Smith (Ed.), Qualitative psychology: A practical guide to research methods (pp. 51-80). Sage Publications.

Sprecher, S., \& Regan, P. C. (2002). Liking some things (in some people) more than others: Partner preferences in romantic relationships and friendships. Journal of Social and Personal Relationships, 19(4), 463-481. https://doi.org/10.1177/0265407502019004048

Sprecher, S., Treger, S., Fisher, A., Hilaire, N., \& Grzybowski, M. (2015). Associations between selfexpansion and actual and perceived (dis)similarity and their joint effects on attraction in initial interactions. Self and Identity, 14(4), 369-389. https://doi.org/10.1080/15298868.2014.1003592

Sternberg, R. J. (1986). A triangular theory of love. Psychological Review, 93(2), 119-135. https://doi.org/10.1037/0033-295X.93.2.119

Strong, G., \& Aron, A. (2006). The effect of shared participation in novel and challenging activities on experienced relationship quality: Is it mediated by high positive affect? In K.D. Vohs \& E.J.Finkel (Eds.), Self and relationships: Connecting intrapersonal and interpersonal processes (pp. 342-359). Guilford Press. 
Torrance, E. P. (1970). Influence of dyadic interaction on creative functioning. Psychological Reports, 26(2), 391-394. https://doi.org/10.2466/pr0.1970.26.2.391

Treger, S., \& Masciale, J. N. (2018). Domains of similarity and attraction in three types of relationships. Interpersona: An International Journal on Personal Relationships, 12(2), 254-266.

https://doi.org/10.5964/ijpr.v12i2.321

Usborne, E., \& Taylor, D. M. (2010). The role of cultural identity clarity for self-concept clarity, selfesteem, and subjective well-being. Personality and Social Psychology Bulletin, 36(7), 883-897. https://doi.org/10.1177/0146167210372215

Zachopoulou, E., Makri, A., \& Pollatou, E. (2009). Evaluation of children's creativity: Psychometric properties of Torrance's 'Thinking Creatively in Action and Movement' test. Early Child Development and Care, 179(3), 317-328. https://doi.org/10.1080/03004430601078669 